\title{
EDUCAÇÃO AMBIENTAL NA UNIVERSIDADE: CONSTRUINDO POSSIBILIDADES
}

\author{
Edilson Fortuna de Moradillo* e Maria da Conceição Marinho Oki \\ Departamento de Química Geral e Inorgânica, Universidade Federal da Bahia, 40170-290 Salvador - BA
}

Recebido em 18/12/02; aceito em 20/11/03

\begin{abstract}
ENVIRONMENTAL EDUCATION AT UNIVERSITY LEVEL: PROPOSED WAYS Environmental education is a big challenge in this century and the University has an important role to play in it. This paper presents a practical experience of environmental education in the university teaching at the University of Bahia. That experience involves the creation of an interdisciplinary group that has been developing research and teaching activities with interdisciplinary perspectives. The paper also discusses a methodology proposed by this group aiming to include environmental education in science teaching using social and cultural approaches.
\end{abstract}

Keywords: environmental education; interdisciplinarity; science teaching.

\section{INTRODUÇÃO}

Atualmente, a preocupação com o ambiente tem estado presente na vida de grande parte da população em diferentes culturas e países. A mídia tem se encarregado de divulgar, quotidianamente, grandes catástrofes ambientais, naturais ou provocadas pela atividade do homem, muitas vezes de forma genérica e noticiosa. O modelo hegemônico atual de desenvolvimento econômico tem contribuído, em grande extensão, para o agravamento desta situação. A degradação ambiental, que tem ocorrido em nível mundial, tem introduzido novas preocupações. Nos encontros, debates e grandes conferências realizadas para a discussão deste assunto é consensual a necessidade da mudança de mentalidade na busca de novos valores e de uma nova ética para reger as relações sociais, cabendo à educação um papel fundamental nesse processo.

Como educadores e sujeitos instituintes, autores e atores da realidade sócio-histórica, temos nos preocupado com estas questões e procurado contribuir, através da nossa prática pedagógica, para educar ambientalmente através da química. Para alcançarmos o nosso objetivo iniciamos, há sete anos, uma aproximação com a Faculdade de Educação da Universidade Federal da Bahia, através da criação de um grupo de estudo, pesquisa e extensão, que congrega pessoas interessadas no estudo e prática da Educação Ambiental nos diversos níveis de ensino e tem como principais objetivos:

- realizar estudos que contribuam para o processo de discussão e construção do conhecimento filosófico, sócio-político-cultural e pedagógico e da sua utilização na formação dos nossos alunos, com ênfase na questão ambiental;

- intercambiar experiências com outros grupos e instituições interessadas nas questões educacionais e sócio-políticas-ambientais;

- prestar consultoria em Educação Ambiental a instituições governamentais ou não governamentais;

- produzir materiais didático-pedagógicos de fundamentação teórico-prática em Educação Ambiental visando contribuir para a melhoria da qualidade de vida da população.

O Núcleo de Estudos em Ciências e Educação Ambiental (NECEA) pertence à Faculdade de Educação da UFBA, mas é atualmente integrado por professores de Educação, Química e Biologia

*e-mail: edilson@ufba.br tendo, portanto, em sua própria constituição, um caráter interdisciplinari. O nosso grupo tem desenvolvido várias atividades principalmente de extensão e, atualmente, estamos finalizando um Curso de Especialização em Educação Ambiental, que durante aproximadamente um ano e meio já formou vinte e cinco educadores ambientais. Está prevista a continuação desta atividade que deverá dar início à capacitação de uma nova turma ainda em 2003, com pelo menos trinta e cinco novos candidatos já inscritos. Os nossos alunos são predominantemente professores do ensino fundamental e médio, além de alguns profissionais que atuam em Organizações Não Governamentais (ONGs).

Outras atividades foram desenvolvidas por alguns professores do grupo, a exemplo da prática da Educação Ambiental em alguns bairros da periferia de Salvador, em parceria com ONGs e atividades curriculares em comunidades. Algumas destas ações envolveram parcerias universidade/escolas públicas da nossa cidade, constituindo-se em atividades de extensão universitária.

\section{A EDUCAÇÃO AMBIENTAL ATRAVÉS DAS CONFERÊNCIAS INTERNACIONAIS ${ }^{1}$}

Importantes eventos mundiais marcaram a trajetória da Educação Ambiental nas últimas décadas. O primeiro deles foi a Conferência da Organização das Nações Unidas sobre o Ambiente Humano, a Conferência de Estocolmo, realizada em 1972, que aconteceu ao mesmo tempo em que o Clube de Roma, formado por vários países ricos, publicava um importante documento, um relatório sobre o crescimento demográfico e a exploração dos recursos naturais, fazendo previsões desagradáveis sobre o futuro da humanidade. A importância deste documento denominado "Limite de Crescimento" deve-se ao fato de ter denunciado os limites da exploração do nosso planeta e a sua fragilidade.

A Conferência de Estocolmo marcou, no nível internacional, a necessidade de políticas ambientais, reconhecendo a Educação Ambiental como uma necessidade para a solução dos problemas ambientais. Nesse encontro também foram propostas orientações para a capacitação de professores e o desenvolvimento de novos métodos e recursos instrucionais para a implementação da Educação Ambiental nos diversos países.

Ao longo das décadas de 70 e 80 , a UNESCO promoveu três conferências internacionais para atender às recomendações feitas no 
Encontro de Estocolmo e que resultaram em três importantes declarações sobre o tema Educação Ambiental. Em 1975, a Conferência de Belgrado produziu a Carta de Belgrado e um Programa Internacional de Educação Ambiental (PIEA). Este programa mantém uma base de dados com informações sobre instituições e projetos envolvidos com a Educação Ambiental, além de promover eventos e publicações específicas sobre este tema.

O segundo encontro promovido pela UNESCO, a Conferência de Tbilisi, realizada em 1977 na cidade de Tbilisi, na Geórgia, constituiu-se na primeira Conferência Intergovernamental. A declaração produzida nesta reunião contém objetivos, estratégias, características, princípios e recomendações para a Educação Ambiental que foram aperfeiçoados em publicações posteriores da UNESCO em 1985, 1986, 1988 e 1989. Nesse documento encontram-se, por exemplo, recomendações para que a Educação Ambiental aconteça tanto ao nível da educação formal quanto da informal, envolvendo pessoas de todas as idades.

A terceira conferência foi realizada em agosto de 1987 em Moscou, e destacou-se das demais por criar um quadro teórico-metodológico para a concretização da Educação Ambiental, sugerindo uma reorientação do processo educacional. Entre os objetivos dessa conferência estava um plano de ação para a implementação da Educação Ambiental ao longo da década de 90.

Embora vários outros encontros menores tenham acontecido para tratar as dimensões sócio-ambientais, a Organização das Nações Unidas (ONU) promoveu ainda outra importante reunião, realizada em 1992, no Rio de Janeiro, a Conferência das Nações Unidas para o Meio Ambiente e Desenvolvimento, também conhecida como Conferência de Cúpula da Terra ou Rio 92. Esse encontro envolveu muita polêmica durante a sua realização e aprovou cinco acordos oficiais internacionais sobre temas como Meio Ambiente e Desenvolvimento, Florestas, Mudanças Climáticas, Diversidade Biológica, além da famosa Agenda 21 que contém pressupostos para a implementação da Educação Ambiental, visando a sobrevivência dos povos para o século XXI. Neste documento foram apresentados compromissos e intenções para uma melhoria da qualidade de vida e da sua sustentabilidade.

Em paralelo a esse evento, o Ministério da Educação e Desportos (MEC) organizou um Encontro onde foi aprovado o documento "Carta Brasileira Para a Educação Ambiental" que enfoca o papel do estado em relação à Educação Ambiental e sua implementação em todos os níveis de ensino.

Embora o conteúdo das várias declarações produzidas nos encontros anteriormente citados tenha recebido muitas críticas, devem ser reconhecidos os avanços introduzidos e que estão contidos nos pressupostos pedagógicos que nortearam estas declarações.

No ano de 2002 aconteceu outro importante evento, a "Rio + 10", na África do Sul, na cidade de Joanesburgo, onde foi feito um balanço das ações sócio-ambientais realizadas na última década, após a Rio-92. Mais uma vez constatou-se a necessidade de todas as nações se engajarem na tarefa de preservação do nosso planeta, assumindo as responsabilidades que cabem a cada uma delas, visando o cumprimento efetivo de compromissos já assumidos. Percebeu-se, também, a dificuldade de fazer com que certos países desenvolvidos reconheçam a grande responsabilidade que lhes cabe na implementação de medidas de proteção do ambiente e da vida, em especial, quando as medidas a serem adotadas vão levar a uma diminuição da produção industrial e do consumo.

\section{A TRAJETÓRIA DA EDUCAÇÃO AMBIENTAL NO BRASIL}

No Brasil, a Educação Ambiental tem enfrentado numerosas dificuldades para o seu reconhecimento efetivo e implementação em to- dos os níveis do ensino formal, bem como no não formal. Estas dificuldades estão essencialmente associadas à política adotada no Brasil, principalmente na década de 90 , que se pautou na implementação de um Estado Mínimo e na submissão da nossa sociedade às regras impostas pelo mercado econômico e pelo capitalismo desenfreado.

Vários documentos atestam que a preocupação ambiental esteve presente no âmbito governamental em nosso país, nos últimos 50 anos, mas, restringindo-se a um enfoque naturalista e preservacionista. Através desta visão, a Educação Ambiental instalou-se no plano federal governamental em nosso país.

A oficialização da Educação Ambiental no Brasil aconteceu através da lei federal de $n^{0} 6.938$, sancionada a 31 de agosto de 1981, que criou a Política Nacional do Meio Ambiente (PNMA). Apesar do atraso em relação às recomendações da Conferência de Estocolmo, esta lei foi promulgada graças ao trabalho e empenho de setores da sociedade como partidos de esquerda, ONGs, ambientalistas e acadêmicos.

No nível governamental federal, vários órgãos estiveram envolvidos com a implementação da educação ambiental, seja na vertente ambiental ou na área educacional, através de vários programas e diretrizes como o PRONEA (Programa Nacional de Educação Ambiental), DEA (Diretrizes de Educação Ambiental), o PEPEA (Programa de Estudos e Pesquisa em Educação Ambiental).

Outra importante ação no nível educacional foi a inclusão da questão ambiental na Lei de Diretrizes e Bases da Educação Brasileira (LDB/96), que passou a considerar a compreensão do ambiente natural como fundamental para a educação básica. A inclusão da área de Meio Ambiente como um dos temas transversais nos Parâmetros Curriculares Nacionais (PCNs) encontra-se enfocada no seguinte trecho desse documento que traz orientações para o trabalho do professor: "O trabalho pedagógico com a questão ambiental centra-se no desenvolvimento de atitudes e posturas éticas e, no domínio de procedimentos, mais do que na aprendizagem de conceitos"'. Mais recentemente, o Senado aprovou a lei federal 9.795, em 27 de abril de 1999, que tem como objetivo oficializar a presença da Educação Ambiental em todas as modalidades de ensino.

Apesar de alguns avanços, a política federal para a Educação Ambiental ainda carece de maior articulação entre os setores governamentais e não governamentais, para que políticas específicas necessárias sejam efetivamente implementadas.

Na década de 80 , o artigo de Krasilchik ${ }^{3}$ foi pioneiro na descrição da evolução da Educação Ambiental no Brasil. Nesse trabalho, essa pesquisadora já constatava a utilização de diferentes concepções de Educação Ambiental, o que ocasionava uma grande diversidade de práticas e um questionamento da qualidade dos trabalhos realizados nesta área, no Brasil. Nesse artigo foram apresentadas sugestões para implementação de programas de Educação Ambiental na educação formal, bem como de pesquisas nesta área.

A ausência de um referencial pedagógico teórico-conceitual para subsidiar as práticas em Educação Ambiental é, ainda hoje, uma importante questão. Deve-se levar em conta também que a educação ambiental não pode prescindir da concepção de uma realidade complexa que inclui diferentes elementos na sua constituição, que estão em contínua interação.

\section{CONCEPÇÕES DE EDUCAÇÃO AMBIENTAL}

Os encontros e debates que tratam da Educação Ambiental apontam para a necessidade de formulação de um quadro teóricoconceitual e metodológico que permita a operacionalização da concepção de Educação Ambiental e a formulação e análise crítica de propostas para a sua implementação.

A base conceitual da Educação Ambiental tem sido objeto de muita discussão pelos pesquisadores e/ou educadores em função do 
caráter interdisciplinar que a caracteriza. Inicialmente, predominava na fundamentação teórica que a orientava uma visão romântica, preservacionista e ecológica. Nas últimas décadas, a educação ambiental passou a ser vista como capaz de prover novos valores, condutas sociais ambientalmente corretas tendo como princípio norteador a ética nas relações sociais.

Segundo Pedrini ${ }^{1}$, "a Educação Ambiental é uma das possibilidades de reconstrução multifacetada não cartesiana do saber humano, constituindo-se num saber construído socialmente e caracteristicamente multidisciplinar na estrutura, interdisciplinar na linguagem e transdisciplinar na sua ação". Ela deve visar a transformação do educando através do desenvolvimento de novos valores, hábitos, posturas, condutas e atos na relação com o ambiente considerado em toda a sua complexidade.

Muitos educadores e pesquisadores ambientais entendem que a Educação Ambiental é um importante referencial de mudança no campo da Educação. Em relação a esse assunto, Reigota ${ }^{4}$ comenta sobre os desafios enfrentados para a sua prática "[...] A Educação Ambiental na escola ou fora dela continuará a ser uma concepção radical de educação, não porque prefere ser a tendência rebelde do pensamento educacional contemporâneo, mas sim porque nossa época e nossa herança histórica e ecológica exigem alternativas radicais, justas e pacíficas".

Dentro de um enfoque construtivista e ambiental, os conhecimentos desejáveis na Educação Ambiental devem estruturar-se como uma síntese integradora de diferentes aportes como, por exemplo, a análise histórica e epistemológica dos conceitos e modelos científicos, a análise da problemática sócio-ambiental relevante no contexto de referência, a análise de concepções prévias e dos procedimentos e valores desejáveis ${ }^{5}$.

A Educação Ambiental deve proporcionar experiências que possibilitem colocar as pessoas em contato direto com o mundo e sensibilizá-las para os ecossistemas que as envolvem; discutir a importância do ambiente para a saúde e o bem estar do homem e para o exercício da cidadania; avaliar o desenvolvimento econômico aliado à degradação ambiental e à qualidade de vida e desenvolver no educando o sentido ético-social diante dos problemas ambientais ${ }^{6}$.

Reconhecemos que o exercício da Educação Ambiental tem encontrado dificuldades que estão associadas à falta de recursos, à pouca valorização do professor, ao pouco envolvimento da comunidade nas decisões e no planejamento escolar, aliada à própria rigidez da estrutura de grande parte das escolas. Outras questões relacionadas à prática pedagógica também devem ser lembradas como a visão "conteudista" que predomina no ensino tradicional, a pouca preparação dos professores e os critérios de avaliação comumente adotados, em que predominam ausência de criatividade e uma visão não processual.

No NECEA compreendemos a Educação Ambiental como um processo de busca do conhecimento, que deve resultar na aquisição de valores que permitam aos indivíduos envolvidos atuar de modo conseqüente no meio em que vivem. Defendemos também que a aquisição do conhecimento fornece elementos para melhor compreensão da realidade e dos problemas que afetam o ambiente na atualidade.

Em nosso entendimento, os três princípios que devem nortear uma prática da educação são: pensar segundo a categoria de totalidade; interpretar os fatos mediante a apreensão histórica do processo de construção do conhecimento e agir no sentido de possibilitar transformações necessárias à dignificação da vida e à implantação de sociedades sustentáveis?

\section{UMA POSSIBILIDADE: A EDUCAÇÃO AMBIENTAL INSERIDA NA PRÁTICA PEDAGÓGICA}

A globalização dos problemas ambientais e a sua compreensão são de responsabilidade do conjunto das sociedades e a educação formal como um dos espaços coletivos para produção/reflexão de conhecimentos torna-se hoje, mais do que nunca, desafiada para inserir nas suas práticas pedagógicas a perspectiva ambiental como um dos eixos norteadores para construção de significados que possam levar à superação do atual contexto sócio-histórico, de degradação e exploração da natureza, incluindo o próprio homem.

A concepção de Educação Ambiental que compartilhamos parte do princípio de que não há ciência sem o homem, seu trabalho e a natureza e que os conteúdos e conceitos devem ser considerados instrumentais básicos para a compreensão da relação Natureza, Conhecimento e Sociedade. Ainda de acordo com essa concepção, o homem é consequiência da interação dialética do "ser como natureza", do "ser como indivíduo" e como condicionante das demais do "ser como relação social". . Em consonância com essa visão do ser humano, o conhecimento, sempre em processo, sem um fim predeterminado é um eterno devir, é algo cultural. A leitura da ciência fora dessa perspectiva traz como consequiência para os indivíduos, a perda da visão de totalidade e a alienação sobre as relações existentes entre ciência e processo cultural, assim como ciência e desenvolvimento social.

O papel da escola, dentro de uma perspectiva política não ingênua, é o de criar espaços através de seus atores e autores sociais no sentido da desalienação dos indivíduos, diante do conhecimento fragmentado e destituído de significado para suas ações sociais.

Nos últimos anos temos feito algumas intervenções em disciplinas oferecidas para químicos e não químicos, no sentido de ter a educação ambiental como um dos eixos centrais para uma prática pedagógica crítica. Assim como Guimarães ${ }^{9}$, defendemos a necessidade da presença da dimensão ambiental na educação.

No curso de Química Geral procuramos trazer à discussão questões relativas à parte básica do ensino superior, dentro da concepção da ciência decorrente das relações sociais, contestando a visão de conhecimento científico considerado único e verdadeiro. $\mathrm{O}$ nosso trabalho tem a intenção de melhorar a motivação dos alunos, bem como possibilitar a reconstrução de certos conteúdos descontextualizados, o que é muito comum no ensino da química.

A metodologia adotada tendo em vista esses pressupostos redirecionou o nosso curso de Química Geral para o modelo sóciocultural de ensino e aprendizagem. Concordamos com Maldaner ${ }^{10}$ em relação à sua proposição de que através de um modelo sóciocultural de ensino e aprendizagem é possível melhorar sensivelmente o nível de conhecimento químico aprendido na escola. Deve-se "superar as propostas tradicionais do ensino de química que colocam todo o esforço do trabalho escolar em torno dos conteúdos descontextualizados, segundo uma lógica de conhecimento sistematizado, que é adequada apenas para quem já conhece química”. Esse pesquisador defende a necessidade de superação das posições que centralizam todo o esforço pedagógico no aluno em contexto escolar, numa postura construtivista, esquecendo que o sentido mais profundo da aprendizagem escolar é o de inserir o aprendiz, de forma intencional e sistemática, no contexto sócio-cultural em que vive.

O nosso curso caracterizado dentro da perspectiva ambiental tem como objetivos:

1) estudar a matéria (constituição, estrutura, propriedades) e suas transformações, incluindo os aspectos cinéticos e energéticos,

2) aplicar os conhecimentos adquiridos a um determinado tema (ar e água, resíduos sólidos, fogo e energia, metais, argilas), procurando relacioná-los com o contexto: ético-político, econômico e cultural; através de seminários realizados pelos alunos e alunas.

\section{ARTICULANDO CONCEITOS QUÍMICOS COM A QUESTÃO AMBIENTAL}

No relato que se segue, utilizaremos como exemplo para ilustrar 
o trabalho desenvolvido o funcionamento de uma disciplina semestral de Química Geral para estudantes do curso de Licenciatura em Ciências. A maioria dos alunos e alunas eram recém-ingressos na Universidade. A disciplina funcionou com $4 \mathrm{~h}$ semanais (68 h no semestre), com módulo de 30 alunos.

Nas primeiras aulas do curso, procuramos identificar as concepções dos alunos sobre a problemática ambiental. O instrumento utilizado foi um questionário envolvendo perguntas sobre ambiente, desenvolvimento sustentável, contexto social, Educação Ambiental. Essas informações constituíram uma referência para o planejamento do ensino e identificação de mudanças no conhecimento dos estudantes ao longo do curso.

Em relação ao conteúdo específico da disciplina, compartilhamos da idéia que a grande função do professor é inserir o aluno no processo de enculturação dentro da dinâmica em sala de aula ${ }^{11}$. Dentro desta perspectiva torna-se imprescindível o levantamento do conhecimento prévio visando o confronto destas idéias com a perspectiva científica apresentada pelo professor. Consideramos importante, por exemplo, saber como os estudantes conceituavam os estados sólido, líquido e gasoso, qual a noção que possuíam do termo partícula material e da sua natureza. Entendemos que este último conceito é fundamental na explicação do comportamento microscópico da matéria e na sua relação com as suas propriedades macroscópicas e os fenômenos físicos e químicos observados. Percebemos que este é um conceito que não é bem compreendido pelos alunos que ingressam na Universidade, tornando difícil que aconteça uma aprendizagem significativa de outros conceitos relacionados a este e que são posteriormente inseridos.

Em um primeiro momento, como estratégia para o levantamento das concepções prévias relativas à matéria, fornecemos aos alunos três tubos fechados contendo materiais em diferentes estados físicos: sólido, líquido e gasoso (um em cada tubo). Em seguida esta situação foi explorada através de um questionário contendo questões que mapearam os conceitos importantes que fazem parte da teoria cinético-molecular da matéria. As respostas foram posteriormente discutidas com os alunos visando compará-las com os conceitos científicos introduzidos pelo professor.

Num segundo momento, as concepções prévias relacionadas com o tema energia e reações químicas foram mapeadas a partir de um experimento simples como a combustão de uma vela. Conceitos como conservação, conversão e transferência de energia foram discutidos, assim como calor de reação.

Na sala de aula priorizamos o tipo de abordagem comunicativa, interativa e dialógica ${ }^{12}$. As idéias eram exploradas pelo professor e estudantes conjuntamente e os diferentes pontos de vistas eram discutidos e avaliados.

As aulas expositivas, realizadas pelo professor, tiveram como finalidade introduzir os assuntos novos, realizar sínteses, manter o rumo dos objetivos acordados. Nas discussões coletivas que seguiram às exposições, trabalhamos situações-problema próprias da disciplina. Por exemplo, como explicar a produção de calor por uma reação de combustão. As explicações dos alunos envolvendo questões como transformação, liberação ou absorção de energia, etc. foram submetidas à crítica do grupo, os estudantes foram estimulados a tomar partido de uma ou outra explicação. Daí emergiram problemas conceituais, como natureza teórica ou empírica da conservação da energia, a diversidade dos conceitos de calor, medidas da energia, interpretação de expressões matemáticas, explicação microscópica das reações de combustão e a representação química dos fenômenos. Desse modo, exercitamos a cooperação entre os alunos na busca das soluções dos problemas propostos, discutimos as razões para optar por um ou outro encaminhamento, exploramos as conexões entre teoria e experiência e analisamos alguns aspectos da bibliografia recomendada para a disciplina.
Em articulação com as questões específicas da química, discutimos também sobre mudança conceitual e resistência (os conceitos históricos de calor e sua confusão com a temperatura e a energia), conexões entre descrição textual e formal dos fenômenos. Em suma, tratamos de agir e refletir coletivamente, buscando um aprimoramento da ação.

Partimos do pressuposto que ao tratar determinados conceitos da Química, não é necessário esgotar tais conceitos para podermos aplicá-los no contexto sócio-cultural do aprendiz ${ }^{13}$. Em seguida à exposição do professor e à discussão coletiva, um grupo de estudantes, através de um tema pré-selecionado e com questões norteadoras previamente formuladas em parceria com o professor, apresentava um seminário onde procurava "revisitar" alguns conceitos fundamentais da Química. Nesse momento procurava-se fazer a inserção destes conceitos dentro da problemática ambiental numa perspectiva ético-política, econômica e cultural.

No curso foram apresentados cinco seminários em equipes, com carga horária total de $15 \mathrm{~h}$. A seguir apresentamos o esquema elaborado para a apresentação de um seminário explorado por um dos grupos de estudantes.

\section{TEMA DO SEMINÁRIO 1: FOGO E ENERGIA}

O principal objetivo era explorar os aspectos conceituais da Química, assim como os seus aspectos sócio-culturais.

Questões norteadoras sobre o tema que foram propostas e desenvolvidas pelos alunos:

- O fogo através do tempo: conservação e domínio

- Conceito de fogo

- O triângulo do fogo e sua importância

- Classes de incêndios

- Energia e suas fontes

- Matriz energética atual e novas possibilidades: problemas econômicos e ambientais

- O acesso à energia e o seu consumo

- O padrão de consumo energético no Brasil, a sua relação com o atual modelo econômico e tecnológico e suas conseqüências

- A visão de mundo que permeia a produção e o consumo energético e suas implicações no campo ético-político

Nos seminários, alguns conceitos chave, por exemplo educação ambiental, ambiente, degradação, conservação, desenvolvimento sustentável, entre outros relacionados à questão ambiental eram trabalhados e sempre retomados. Estes conceitos eram discutidos visando a compreensão do ambiente em sua totalidade a partir de uma perspectiva sócio-histórica, contribuindo para que a química fosse percebida como um empreendimento cultural. Fazia parte também da nossa proposta criar entre os alunos uma perspectiva crítica sobre a cultura científica e as suas consequiências.

A pesquisa $a^{\text {ii }}$ e apresentação de seminários, a participação nas atividades em sala de aula e externas $^{\mathrm{iii}}$, as resoluções de exercícios e a freqüência foram instrumentos da avaliação, que adotou uma linha processual. Os alunos avaliaram positivamente o curso, sempre ressaltando que a aplicação dos conceitos principais estudados durante o curso dentro da perspectiva sócio-ambiental, saindo de uma exploração simplista do tripé ambiente-química-poluição, enriqueceu o curso ao facilitar a apropriação/contextualização dos conteúdos, favorecendo uma visão não reducionista de ambiente.

Pretendemos, desse modo, cativar os nossos alunos tornando o conteúdo programático mais atraente e adequado à realidade social, através de reflexões sobre os significados contemporâneos de conhecimento, ciência, cultura, educação, dentre outros, aliado a debates profundos das questões éticas e morais surgidas com os proces- 
sos de desenvolvimento, principalmente da ciência e tecnologia. A nossa prática pedagógica tem sido direcionada para contemplar estas questões.

\section{REFERÊNCIAS}

1. Pedrini, A. de G. Em Educação Ambiental: reflexões e práticas contemporâneas; Pedrini, A. de G., org.; $3^{\mathrm{a}}$ ed.,Vozes: Petrópolis, 2000, cap. i.

2. Brasil, Secretaria de Educação Fundamental; Parâmetros curriculares nacionais: terceiro e quarto ciclos: apresentação dos temas transversais/ Secretaria de Educação Fundamental, Brasília: MEC/SEF, 1998, p. 201.

3. Krasilchik, M.; Ciência e Cultura 1986, 38, 1958.

4. Reigota, M. Em Educação, Meio Ambiente e Cidadania; Cascino, F.; Jacobi, P.; Oliveira, J. F., org.; SMA/CEAM: São Paulo, 1998.

5. Medina, N. M.; Amazônia, Uma Proposta Interdisciplinar de Educação Ambiental, Ed. IBAMA: Brasília, 1994.

6. Pereira, A. B.; Aprendendo Ecologia Através da Educação Ambiental, ed. Sagra-DC Luzzatto: Porto Alegre, 1993.

7. Araujo, A. R.; Moradillo, E. F.; Pimentel, H. O.; Melo, H. T.; Souza, J. B.; Constante, J. P.; Oki, M. C. M.; Carvalho, M. L. S. M.; Pinho, R. C.; Lôbo, S. F.; Zacarias, T. M.; Paradella, Y. P.; Projeto: Criação/implantação do Núcleo de Estudos em Ciências e EducaçãoAmbiental (NECEA), FACED/UFBA, Salvador, 1995.

8. Frigotto, G. Em Eucação e Crise do Trabalho: Perspectivas de Final de Século; Frigotto, G., org.; Vozes: Petrópolis, 1998, cap. 1.

9. Guimarães, M. A.; A Dimensão Ambiental na Educação, Papirus: Campinas, 1995

10. Maldaner,O. A.; Anais do VIII Encontro Nacional de Ensino de Química; VIII Encontro Centro Oeste de Debates Sobre o Ensino de Química e Ciências, Campo Grande, Brasil, 1996.

11. Driver, R.; Leach, J.; Mortimer, E. F.; Scolt, P.; Química Nova na Escola 1999, 9, 31.

12. Mortimer, E. F.; Scott, P.; Investigações Em Ensino de Ciências, 2002, 7, ou em http://www.if.ufrgs.br/public/ensino/revista.html, acessada em Abril 2003.

13. Mortimer, E. F.; Quim. Nova 2000, 23, 273.

14. Fazenda, I. C. A.; Integração e Interdisciplinaridade no Ensino Brasileiro: Efetividade ou Ideologia, Loyola: São Paulo, 1996.

\section{NOTAS}

${ }^{\mathrm{i}}$ Como o conceito de interdisciplinaridade não possui um sentido único e estável, citaremos alguns pontos que consideramos es- senciais a uma interdisciplinaridade de acordo com a discussão que é feita por Fazenda ${ }^{14}$ :

a) a mudança na atitude frente ao problema do conhecimento, na substituição de uma concepção fragmentária pela concepção unitária do ser humano;

b) a colaboração entre as diversas disciplinas conduzindo a uma "interação", a uma intersubjetividade que pode levar à realização de objetivos comuns, a partir de pontos de vista diferentes, visando uma mudança no modo de compreender e entender;

c) a superação dos obstáculos psicossociológicos, culturais e materiais visando uma nova pedagogia, a da "comunicação".

ii Bibliografia complementar geral fornecida para preparação dos seminários:

1. Benn, F. R.; Mcauliffe, C. A.; Química e poluição, trad. de Pitombo, L. R. L.; Massaro, S., EDUSP: São Paulo, 1981.

2. Lago, A.; Pádua, J. A.; O que é ecologia, Brasiliense: São Paulo, 1984

3. Leite, J. L., org.; Problemas chave do meio ambiente, ed. EXPOGEO: Salvador, 1994.

4. Lima, M. J. de A.; Ecologia Humana, Vozes: Petrópolis, 1984.

5. Pereira, N. S.; Pereira, J. Z. F.; Terra, planeta poluído, ed. SAGRA: Porto Alegre, 1980.

6. Reigota, M.; O que é educação ambiental, Brasiliense: São Paulo, 1994.

7. Vidal, J. B.; De Estado servil a Nação soberana, Vozes: Petrópolis, 1988.

8. Vidal, J. B.; Soberania e dignidade, Vozes: Petrópolis, 1991.

Foram consultados também livros paradidáticos de conteúdos específicos relacionados aos temas dos seminários, bem como páginas da internet e materiais técnicos fornecidos por algumas instituições.

iii Alguns dos temas que foram objeto de pesquisa e discussão posterior em seminários motivaram a visita de alunos a instituições, tais como Empresa Baiana de Águas e Saneamento, Fábrica de Materiais Cerâmicos, Central de Tratamento de Efluentes do Polo Petroquímico da Camaçari/CETREL, Prefeitura Municipal de Salvador/LIMPURB, etc., para conhecer melhor os processos químicos de produção e a problemática sócio-ambiental relacionada ao tema escolhido. 